\title{
Performance Evaluation of the Developed Mechanical Actuator
}

\author{
Md. Hazrat Ali ${ }^{{ }^{*}}$, Akio KATSUKI ${ }^{\mathrm{b}}$, Anatoli VAKHGUELT ${ }^{\mathrm{c}}$ \\ ${ }^{\mathrm{a}, \mathrm{c}}$ School of Engineering, Nazarbayev University, Astana, Kazakhstan. \\ ${ }^{\mathrm{b}}$ Kyushu University, Fukuoka, Japan. \\ Corresponding Author: ${ }^{* 1}$ md.ali@nu.edu.kz
}

\begin{abstract}
This paper presents the characteristics of the developed mechanical actuator in measuring deep-hole parameters while comparing the performance with other types of existing actuators. Mechanical actuators are necessary in many applications and one of them is to actuate the loads of the work piece during measurement. Depending on our needs, actuators can be selected by observing its characteristics and overall performance. This research focused on the development of such mechanical actuator in order to use apply it in measuring deep-hole (L/D>3) parameters such as roundness, cylindricity, etc.
\end{abstract}

Keywords: Accuracy, Actuator, Measurement, Performance, Surface.

\section{Introduction}

In mechanical system and engineering, measurement is very important in order to verify the efficiency of the machines, tools, various manufactured parts and components. In precision measurement, piezoelectric actuator is used due to its high response characteristics. As the piezoelectric actuator is very expensive and it has a hysteresis error, this is not very effective in precision measurement. To solve this problem, mechanical actuator can be implemented successfully in measuring hole surface parameters. Some experimental results have shown that mechanical actuators can carry a load up to $16 \mathrm{~kg}$ [1, 2, 3, and 4]. Measurement of a long deep-hole's accuracy is very important as well as difficult. Mechanical actuator can help to ease this problem [1]. Past studies that have applied the piezoelectric actuators in order to control tool attitude during measurement, have several disadvantages such as allowable load is up to $16 \mathrm{~kg}$, the stroke of the supporting pad is small, creates hysteresis loop, and it is expensive as well. In another study, separate measurement method for deep hole described and shown that it is also possible to measure and compare the measured deep-hole data with acquired data by electric micrometer and roundness tester [2].Deep-hole with 3m-length and $63 \mathrm{~mm}$-diameter was measured by the measurement unit with the cylindrical long measurement bar using piezoelectric actuators [4]. In [3], piezoelectric actuators are applied with the measurement unit which can measure holes with a diameter of 70 to $168 \mathrm{~mm}$. In all those previous studies, piezoelectric actuators are used due to its advantages. Piezoelectric actuator has a stroke of $0.35 \mathrm{~mm}$, allowable load is $16 \mathrm{~kg}$ and response speed is also very fast. The main advantage of piezoelectric actuator is that it is very expensive. The objective of the current study is to discuss and compare the characteristics of developed mechanical actuator.

\section{Actuator}

An actuator is a type of motor for driving or moving or controlling a mechanism or system. It is operated by a source of energy, usually in the form of an electric current, hydraulic fluid pressure or pneumatic pressure, and converts that energy into some kind of motion or displacement. The common forms of actuators are mechanical, pneumatic, hydraulic, or electric solenoids or motors.

\subsection{Pneumatic actuator}

All A simplified diagram of a pneumatic actuator is shown in Figure 1. It operates by a combination of force created by air and spring force. The actuator position controls the valve by transmitting its motion through the stem [5]. 


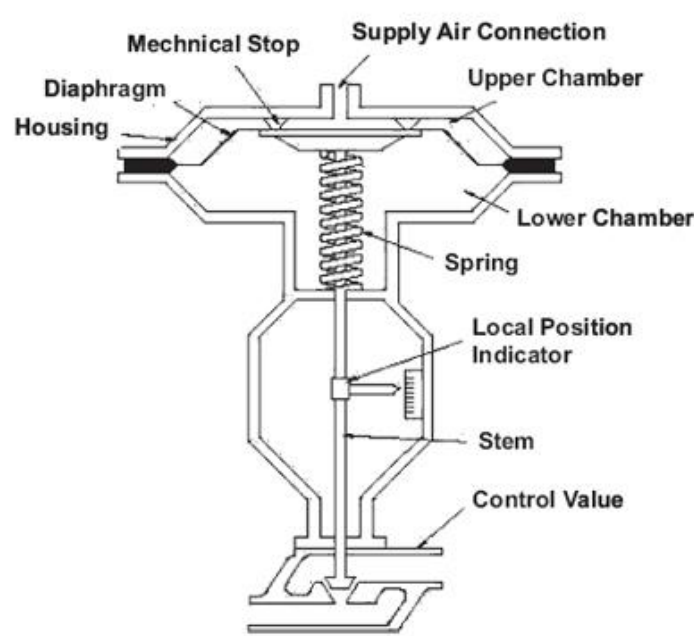

Fig.1. Pneumatic actuator: air-to-close/spring-to-open

\subsection{Hydraulic actuator}

Hydraulic actuators normally consist of a hollow cylinder having a piston inserted in it. Strong pressure applied to the piston in order to generate force that can move an external object. Since liquids are nearly incompressible, a hydraulic cylinder can provide controlled precise linear displacement of the piston. The displacement is only along the axis of the piston and this makes this type of actuator not applicable for multiple axes purpose. Typically, hydraulic actuator refers to a device controlled by a hydraulic pump which is also drive by the electric motor.

\subsection{Electro-mechanical actuator}

It provides more precise and reliable motion, and integrates easily with modern PLCs and computers. From a complete system perspective, they are smaller, lighter, and cleaner than their hydraulic counterparts. Figure 2 shows a functional diagram of electro-mechanical actuator [6]. Electro-mechanical actuators have the following advantages. Increase efficiency, therefore reducing energy consumption. For battery-driven electric vehicles, this means increased battery life. Eliminate hydraulic hoses, valves and pumps.

Have support systems that take up less space, by replacing fluid reservoirs and valve banks with compact electronic drives. Eliminate the hassle and cost of dealing with spent hydraulic oil. Remove the functional reliability risk associated with hydraulic fluid contamination. Eliminate the safety and environmental issues of oil leaks.

\section{ELECTRO-MECHANICAL ACTUATION}

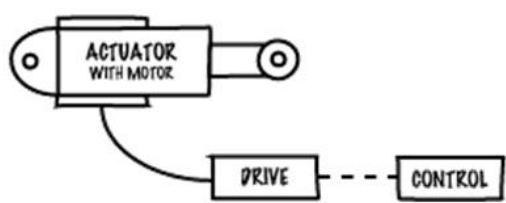

Fig.2. Electro-mechanical actuator

\subsection{Piezoelectric actuator}

Piezoelectric actuators are devices that produce a small displacement with a high force capability when voltage is applied. There are many applications where a piezoelectric actuator may be used, such as ultra-precise positioning and in the generation and handling of high forces or pressures in static or in dynamic situations [7]. Figure 8 shows a PI type piezoelectric actuator [8].

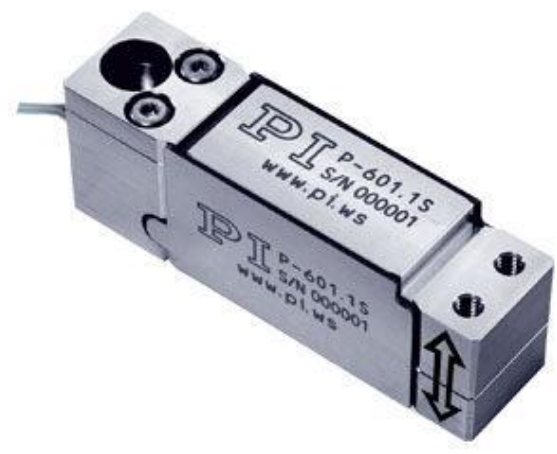

Fig.3. Piezoelectric Actuator

\subsection{Mechanical actuator}
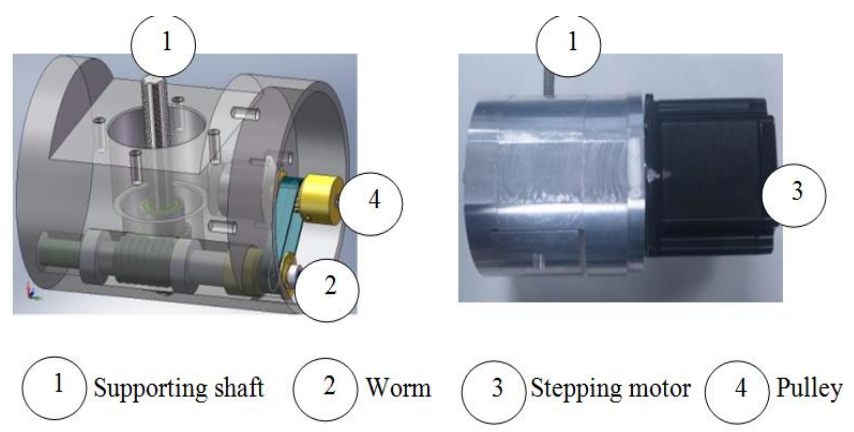

Fig.4. Mechanical Actuator

Figures 4 and 5 show the developed actuator and its internal apparatus that were used earlier for measurement purpose. Figure 5 has the piezoelectric actuators whereas Figure 4 does not have piezoelectric actuators. In Figure4, the stepping motor is connected to the actuator in order to push 
and pull it upwards as well as downwards, respectively. Worm and worm wheel transfer the rotational speed to the supporting shaft through belt and pulley system. The supporting shaft's movement is controlled via servo motor controller. This experiment was conducted in relation to the load and speed of the supporting shaft. The worm and worm wheel system integrated with pulley and belt is essential in order to transform the rotational motion into linear motion. It was done by calculating the appropriate gear ratio.

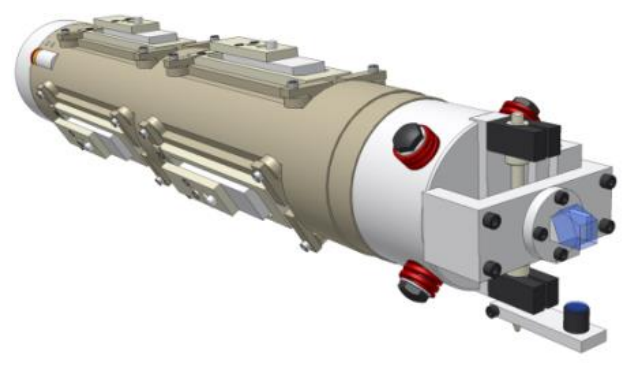

Fig.5. Measurement probe

\section{Results and Discussion}

\subsection{Mechanical actuator's feed control}

Figure 6 shows the screen shot for operating the motor and control its speed through software.

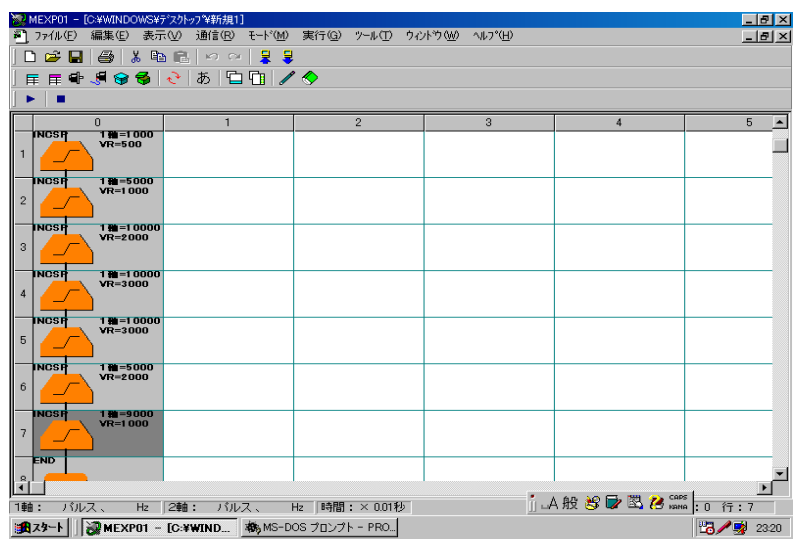

Fig.6. Speed and time controller

Figure 7 and Table 1show an experimental condition applied during a primary test. In this test, variable speed parameters were selected at different times. Maximum speed duration was $10 \mathrm{~s}$ in this experiment where the input impulse was 3000 VR. This is to observe the behaviour of the actuator at variable loads and input pulse.

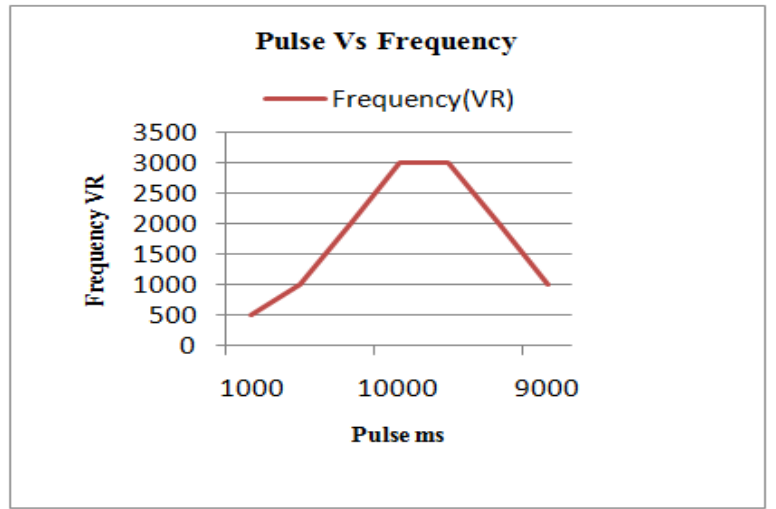

Fig.7. An example of pulse vs frequency controller

Table 1.Speed and time control

\begin{tabular}{|r|r|}
\hline Pulse(ms) & Frequency(VR) \\
\hline 1000 & 500 \\
\hline 5000 & 1000 \\
\hline 10000 & 2000 \\
\hline 10000 & 3000 \\
\hline 10000 & 3000 \\
\hline 5000 & 2000 \\
\hline 9000 & 1000 \\
\hline
\end{tabular}

It is noticeable that the actuator had vibration during lifting the load upward while there was no vibration during pulling the load download.

\subsection{Characteristics of piezoelectric actuator}

Comparing mechanical actuator to a piezoelectric actuator in Figure 8 we observed that the stroke is $0.35 \mathrm{~mm}$ in piezoelectric actuator whereas in the developed system the stroke is almost $40 \mathrm{~mm}$. In the developed system the hysteresis error does not exist. Measurement error is not likely to occur even if the load varies during the measurement. In measuring deep hole surface parameters, we may not require more than $50 \mathrm{~mm}$ stroke. But with the expensive piezoelectric actuator can lift only the few $\mathrm{mm}$. which is not enough for many other types of deep hole components. 


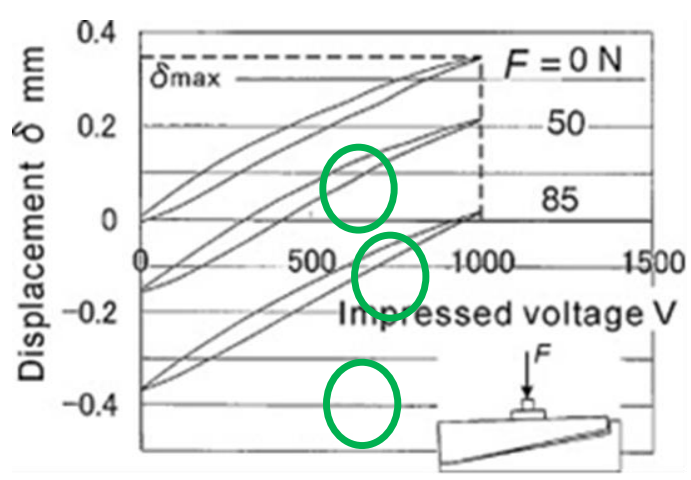

Fig.8. Hysteresis of piezoelectric actuator

\subsection{Justification of mechanical actuator using electric} micrometer

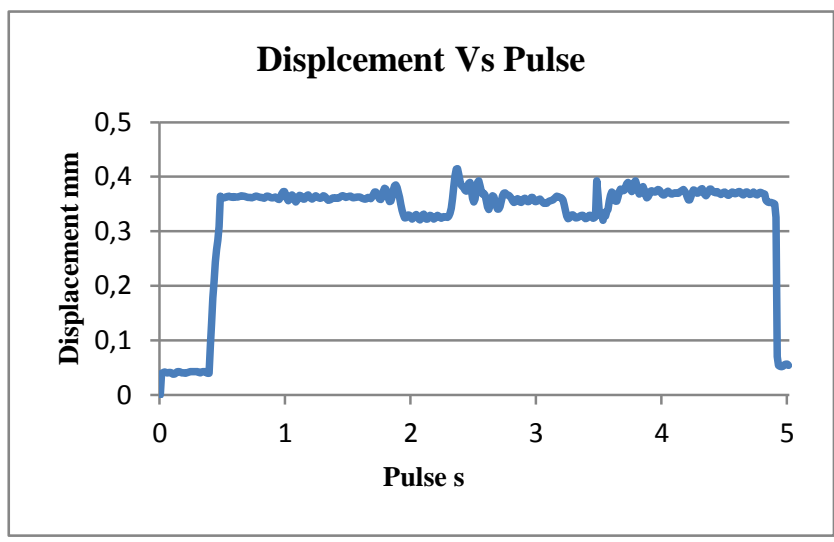

(a)

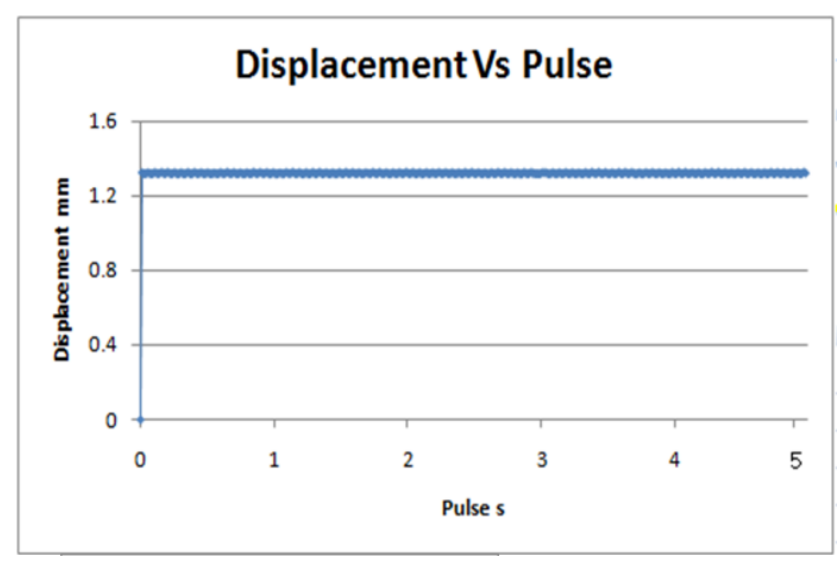

(b)

Fig.9. Actuator's response using electric micrometer $(a, b)$

Figure $9(\mathrm{a}, \mathrm{b})$ shows experimental results of a small actuator. The first figure shows the fluctuating data of the system where as the second figure shows the stable data. Fluctuation sometimes generates errors during experiment.
This kind of small actuator can be used for lifting light weight during measurement. This experiment carried out with the help of electric micrometer where mechanical actuator was integrated with the electric micrometer.

\subsection{Justification of mechanical actuator applying low torque motor}

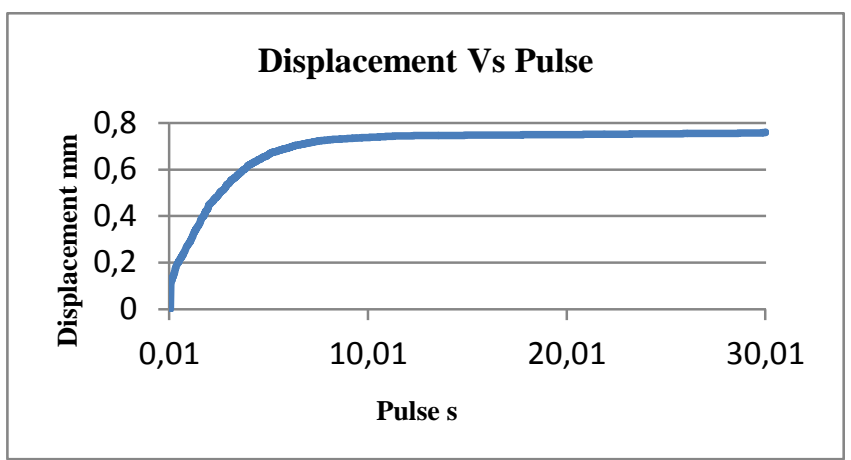

Fig.10. Actuator's response applying low torque motor

Figures 10 and 11 show experimental data of another type of actuator which could lift the load up to a height of 0.8 mm during measurement with a small load applied on it. This is still more than the stroke of piezoelectric actuator. Small and low torque motor is applied to conduct this experiment. Low torque motor has less vibration but the limitation is on its maximum lifting capacity. Maximum lifting weight is about $1 \mathrm{~kg}$.
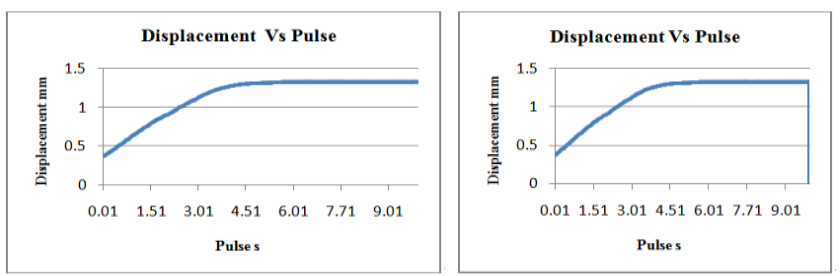

Fig.11.Actuator's response applying low torque motor

\subsection{Mechanical actuator for a load of $1.1 \mathrm{~kg}$}

Figure 12 and Table 2 show experimental data of another type of actuator which could carry a load up to a $1.1 \mathrm{~kg}$ and lifting height between 27.5 to $38 \mathrm{~mm}$ during measurement tests based on the applied load. A little vibration can be seen throughout the lifting distance. 


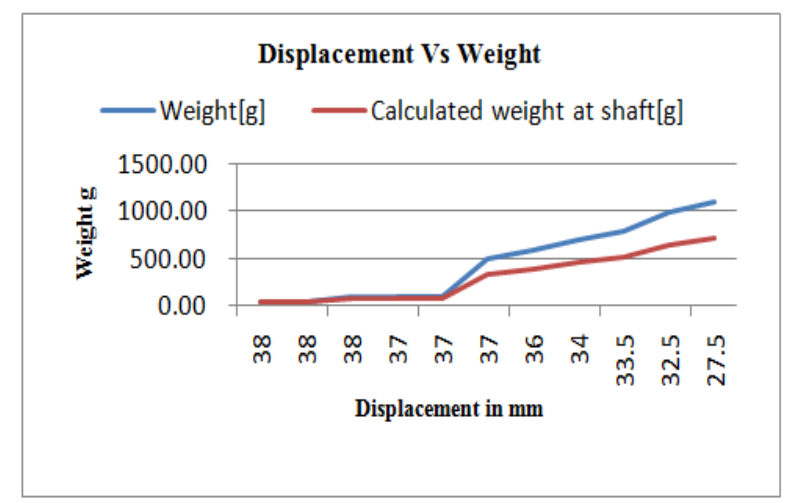

Fig.12. Actuator's response while carrying a load of $1.5 \mathrm{~kg}$

Table 2. Shows weight vs distance

\begin{tabular}{|c|c|c|c|c|c|}
\hline No & Weight[g] & Calculated weight at shaft Distance pushed[mm] & Time[s] & Pulse distance(from0P300) \\
\hline 1 & 50.01 & 32.86 & 38.0 & 30 & 50000 \\
\hline 2 & 50.88 & 33.44 & 38.0 & 30 & 50000 \\
\hline 3 & 102.14 & 67.12 & 38.0 & 30 & 50000 \\
\hline 4 & 102.98 & 67.67 & 37.0 & 30 & 50000 \\
\hline 5 & 103.89 & 68.27 & 37.0 & 30 & 50000 \\
\hline 6 & 500.00 & 328.57 & 37.0 & 30 & 50000 \\
\hline 7 & 600.12 & 394.36 & 36.0 & 30 & 50000 \\
\hline 8 & 700.12 & 460.08 & 34.0 & 30 & 50000 \\
\hline 9 & 800.19 & 525.84 & 33.5 & 30 & 50000 \\
\hline 10 & 1000.00 & 657.14 & 32.5 & 30 & 50000 \\
\hline 11 & 1100.00 & 722.86 & 27.5 & 30 & 50000 \\
\hline
\end{tabular}

\subsection{Mechanical actuator for a load of $16.87 \mathrm{~kg}$}

Figure 13 and Table 3 show experimental data of another actuator which could carry a load up to a $16.87 \mathrm{~kg}$ and lifting height between 26.2 to $31.9 \mathrm{~mm}$ during measurement tests based on the applied load. This has better performance than the one which could lift the weight of 1.1 $\mathrm{kg}$. The displacement tends to be linear even though a small fluctuation can be seen during lifting the load.

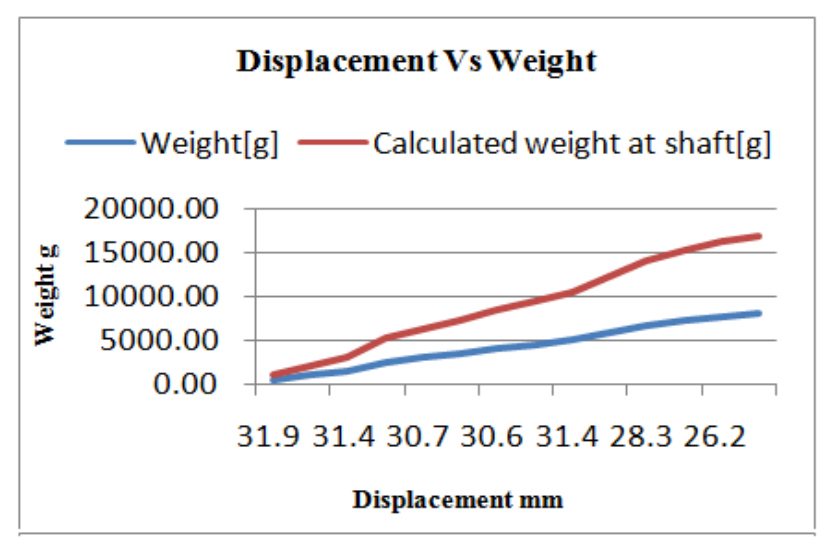

Fig.13. Actuator's response while load is $20 \mathrm{~kg}$
Table 3. Shows weight vs distance

\begin{tabular}{|c|c|c|c|c|c|}
\hline No & Weight[g] & Calculated weight at shaft & Distance pushed[mm & Time[s] & Pulse distance(fromOP300) \\
\hline 1 & 500.00 & 1047.62 & 31.9 & 50 & 50000 \\
\hline 2 & 1000.00 & 2095.24 & 31.8 & 50 & 50000 \\
\hline 3 & 1500.00 & 3142.86 & 31.4 & 50 & 50000 \\
\hline 4 & 2500.00 & 5238.10 & 30.9 & 50 & 50000 \\
\hline 5 & 3000.00 & 6285.71 & 30.7 & 50 & 50000 \\
\hline 6 & 3500.00 & 7333.33 & 30.6 & 50 & 50000 \\
\hline 7 & 4000.00 & 8380.95 & 30.6 & 50 & 50000 \\
\hline 8 & 4500.00 & 9428.57 & 30.1 & 50 & 50000 \\
\hline 9 & 5000.00 & 10476.19 & 31.4 & 50 & 50000 \\
\hline 10 & 5890.00 & 12340.95 & 29.0 & 50 & 50000 \\
\hline 11 & 6750.00 & 14142.86 & 28.3 & 50 & 50000 \\
\hline 12 & 7330.00 & 15358.10 & 26.4 & 21 & 50000 \\
\hline 13 & 7730.00 & 16196.19 & 26.2 & 17 & 50000 \\
\hline 14 & 8050.00 & 16866.67 & 0.0 & 0 & 50000 \\
\hline
\end{tabular}

\subsection{Mechanical actuator for a load of $24 \mathrm{~kg}$}

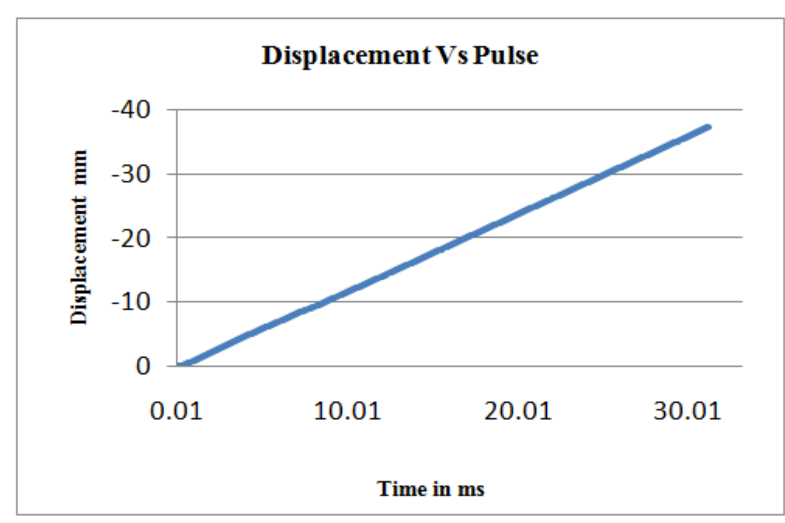

Fig.14.Actuator's response while lifting stroke is $38 \mathrm{~mm}$

Figure 14 shows an experimental data of another actuator which could carry a load up to a $24 \mathrm{~kg}$ and lifting height between 0 to $38 \mathrm{~mm}$ during measurement tests depending on the applied load. We can easily observe that the lifting graph is very smooth. This was due to higher torque motor selection and reasonable load for that motor. The hole surface measurement spindle was approximately $16 \mathrm{~kg}$, so it is necessary to apply this type of motor and actuator in order to replace the piezoelectric actuator and get better performance in terms of higher stroke and loads that are very crucial in measuring hole surface parameter.

\subsection{Performance comparison with other actuators}

From Table 4, we can compare and easily can distinguish the advantage of the developed mechanical actuator compare to other type of actuators in measuring inner hole surface parameters. This type of mechanical actuator is very useful where high precision and accuracy are required. In addition, the mechanical actuator can lift up to a load of $200 \mathrm{~N}$ which is a huge lifting force and can be applied up to this amount of lifting force where it is necessary to pull or push in mechanical system or device. 
Table 4.Performance evaluation of carious actuators for hole surface

\begin{tabular}{|c|c|c|c|c|c|}
\hline Type of Actuator & Control & $\begin{array}{l}\text { Maximum } \\
\text { Load }\end{array}$ & $\begin{array}{c}\text { Hysteresis } \\
\text { Error }\end{array}$ & Accuracy & Cost \\
\hline 1.Pneumatic & $\begin{array}{l}\text { Inherently } \\
\text { non-linear, } \\
\text { compressible } \\
\text { power source } \\
\text { severely } \\
\text { complicates } \\
\text { servo control }\end{array}$ & $\begin{array}{c}\text { Complex } \\
\text { back-up safety } \\
\text { devices must } \\
\text { be used }\end{array}$ & Exist & $\begin{array}{l}\text { Difficult to achieve. } \\
\text { Requires expensive } \\
\text { position sensing and } \\
\text { precise valving to } \\
\text { implement, has } \\
\text { tendency to creep }\end{array}$ & $\begin{array}{c}\text { Costly when } \\
\text { compressor capacity } \\
\text { is not fully utilized, } \\
\text { with additional costs } \\
\text { incurred when a } \\
\text { compressor sits } \\
\text { idling }\end{array}$ \\
\hline 2.Hydraulic & $\begin{array}{l}\text { Hysteresis, dead } \\
\text { zone, supply } \\
\text { pressure and } \\
\text { temperature } \\
\text { changes } \\
\text { complicate } \\
\text { control }\end{array}$ & $\begin{array}{c}\text { Complex } \\
\text { back-up safety } \\
\text { devices must } \\
\text { be used }\end{array}$ & Exist & $\begin{array}{c}\text { Requires expensive } \\
\text { position sensing and } \\
\text { precise } \\
\text { electrohydraulic } \\
\text { valving to implement, } \\
\text { has tendency to creep }\end{array}$ & $\begin{array}{l}\text { Hydraulic power } \\
\text { unit cost is high if } \\
\text { not pre-existing }\end{array}$ \\
\hline $\begin{array}{l}\text { 3.Electro- } \\
\text { mechanical }\end{array}$ & $\begin{array}{c}\text { Feedback } \\
\text { control } \\
\text { necessary }\end{array}$ & $\begin{array}{l}\text { Load varies } \\
\text { with screw } \\
\text { type and the } \\
\text { driving motor }\end{array}$ & Exist & Good & Moderate initial cost \\
\hline 4.Piezoelectric & Not appropriate & Small & Large & Not very accurate & Expensive \\
\hline 5.Mechanical & Simple & $200 \mathrm{~N}$ & Eliminate & Very accurate & Cheap \\
\hline
\end{tabular}

\section{Conclusions}

The purpose of this research is to produce necessary mechanical actuator for controlling the attitude of the measurement probe. We can summarize its performance as below.

$>$ The new mechanical actuator strokes are larger.

$>$ Its allowable load is greater than the piezoelectric actuator which is improved from $160 \mathrm{~N}$ to a maximum of $200 \mathrm{~N}$.

$>$ Hysteresis error is negligible.

$>$ Inexpensive

$>$ Attitude control of the probe is easier.

On the other hand, the advantage of the piezoelectric actuator is its fast response speed. If we need high response actuator then choosing piezoelectric actuator will give better performance.

\section{References}

(1) Akio Katsuki et al, "Development of a Laser-Guided Deep-Hole Measurement System: Automatically adjustable probe to variable hole diameter”. Kanazawa, Japan, 2011.
(2) Akio Katsuki, H. Onikura, T. Sajima, H. Murakami, T. Sato, H. Nishi, V. Pietri, and MD Hazrat Ali, Development of a Laser-guided Measurement System With Lower Production Cost,25 $5^{\text {th }}$ Annual Meeting of the American Society for Precision Engineering Atlanta, USA, 2010

(3) Akio Katsuki, H. Onikura, Takao Sajima, Hiroshi Murakami, Toshiro Doi, Tsuyoshi Sato, MD Hazrat Ali, and Alexandre Berjaud,"Development of a Laser-guided Deep-hole Measurement System with High-performance Mechanical Actuators". The 26th ASPE Annual Meeting, November 13- 18, 2011, Denver, USA.

(4) Akio Katsuki, MD. Hazrat Ali, Takao Sajima, Hiroshi Murakami, and Hiroshima Onikura, "Development of a Laser-guided Deep-hole Measurement System: Usage of Long Measurement Bar", Mechanical Engineering conference December2011, Chittagong, Bangladesh.

(5) http://www.globalspec.com/reference/8269/348308/3-8-actuators.

(6) http://www.americanactuators.com/why_e-m.html.

(7) http://www.globalspec.com/learnmore/electrical_electronic_compone nts/passive_electronic_components/piezoelectric_devices/piezoelectr ic_actuators.

(8) http://www.nanoactuators.com/nano-actuator.php. 